\title{
Visual Hallucinations and Ischemic Stroke: Review of 5 Cases
}

\author{
Songul Senadim ${ }^{1 *}$, Zeynep Ezgi Balcik ${ }^{1}$, Ersin Uygun ${ }^{2}$, Mahir Yusifov ${ }^{1}$, Betul Tekin Guveli ${ }^{1}$, H Dilek Atakli ${ }^{1}$
}

${ }^{1}$ Department of Neurology, Bakırköy Education and Research Hospital for Psychiatric and Neurological Diseases, Istanbul, Turkey

${ }^{2}$ Department of Psychiatry, Bakirkoy Prof. Dr. Mazhar Osman Training and Research Hospital for Psychiatric, Neurologic and Neurosurgical Diseases, Istanbul, Turkey

*Corresponding author: Songul Senadim, Department of Neurology, Bakırköy Education and Research Hospital for Psychiatric and Neurological Diseases, Istanbul, Turkey, Tel: 9005334503717 ; E-mail: songulsenadim@gmail.com

Received date: July 25, 2017; Accepted date: August 26, 2017; Published date: August 31, 2017

Copyright: ( 2017 Senadim S, et al. This is an open-access article distributed under the terms of the Creative Commons Attribution License, which permits unrestricted use, distribution, and reproduction in any medium, provided the original author and source are credited.

\begin{abstract}
Background: Charles Bonnet syndrome (CBS) presents with complex, vivid, repetitive visual hallucinations that occur in people who have lost some of their vision. The most common cause is senile macular degeneration. CBS can occur, rarely, in patients whose visual pathways are affected. We present five patients with complex visual hallucinations who had occipital lobe lesions after ischemic stroke.

Case report: The patients included four men and one woman with a mean age of $71.8 \pm 13.08$ years. The neurological examinations showed left homonymous hemianopsia in four patients and right homonymous hemianopsia in one, plus there was hemiparesis in two patients and ataxia in one patient. An acute ischemic lesion was seen in the posterior cerebral artery territory in all patients on diffusion-weighted magnetic resonance imaging (MRI). Visual hallucinations in the hemianopic area occurred within the first $48 \mathrm{~h}$ of the stroke and lasted from a few minutes to half an hour. Electroencephalography (EEG) taken while symptomatic or shortly thereafter showed mild bioelectrical slowing in the right hemisphere in one patient, while the EEGs of the other patients were normal. During follow-up, the visual hallucinations disappeared in all patients within 3 months, without special treatment.
\end{abstract}

Conclusion: The correct diagnosis of CBS, and treatment if necessary, are important and require an evaluation by a multidisciplinary team that includes neurologists, ophthalmologists, and psychiatrists.

Keywords: Charles Bonnet syndrome; Occipital lobe lesion; Visual hallucination; Ischemic stroke

\section{Introduction}

Charles Bonnet syndrome (CBS) is characterized by complex, vivid, recurrent visual hallucinations that occur in people with no known psychiatric illnesses, normal consciousness and a loss of visual function [1]. This syndrome was first described by the Swedish scientist Charles Bonnet in 1760 based on the visual hallucinations his grandfather Thomas Lullin developed after cataract surgery. Bonnet also developed similar visual hallucinations associated with eye problems when he was older [2]. In 1967, the Swiss scientist George de Morsier called the syndrome Charles Bonnet syndrome [3].

The prevalence of CBS varies ranges from $0.4 \%$ to $15 \%$ in patients with impaired vision [4]. The most common cause is senile macular degeneration, and other causes are glaucoma, cataracts, postenucleation, optic neuritis, macular photocoagulation, Leber's hereditary optic neuropathy, macular translocation, central retinal artery occlusion, and arteritic and non-arteritic anterior ischemic optic neuropathy [5-8]. It is seen more rarely in patients whose visual pathways are affected. Lesions of the occipital lobe are seen in multiple sclerosis, temporal arteritis and meningiomas [9-12].

Simple hallucinations occur with occipital lobe lesions, while complex visual hallucinations are associated with occipitotemporal and occipitoparietal visual association cortex damage [13].

This study presents five patients with complex visual hallucinations seen in our neurology clinic between 2015 and 2017 that were diagnosed with ischemic stroke (acute unilateral/bilateral occipital lobe infarct) in the posterior cerebral artery (PCA) territory and had homonymous hemianopsia on neurological examination.

\section{Case Report}

The patients comprised four men and one woman with a mean age of $71.8 \pm 13.08$ years. All patients had acute-onset visual impairment: one had headache, two had unilateral weakness and one had ataxia. In the neurological examinations, left homonymous hemianopsia was found in four patients and right homonymous hemianopsia in one. In addition to these findings, left hemiparesis was present in two patients and ataxia in one. In their medical histories, four patients had hypertension, one had diabetes mellitus, one had ischemic stroke, and three had coronary artery disease. None of our patients had epilepsy, alcohol or drug abuse, Parkinson's disease, dementia, or psychiatric illnesses.

Diffusion-weighted magnetic resonance imaging (MRI) showed acute ischemic lesions on the right side in two patients, on the left side in one, and bilaterally in the PCA territory in two (Figure 1). Routine laboratory examinations detected hyperlipidaemia in two patients and the other tests were normal in all patients, including serum electrolytes, glucose and liver and kidney functions. 


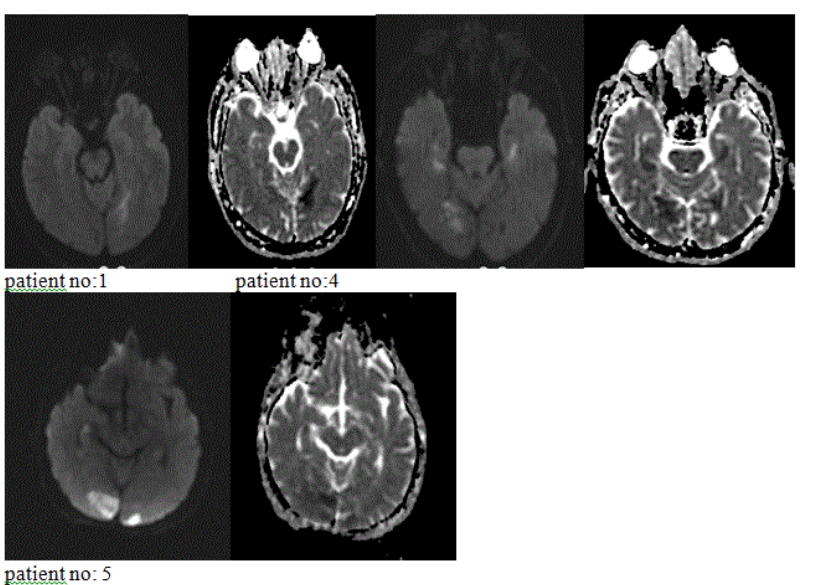

Figure 1: Brain MRI; acute ischemic lesions on the left side in patient no. 1, acute ischemic lesions on the bilaterally in the PCA territory in patient nos. 4 and 5 that were hyperintense on diffusion-weighted images and hypointense on apparent diffusion coefficient images
Within the first $48 \mathrm{~h}$, the patients complained of visual hallucinations in the hemianopic area lasting from a few seconds to half an hour. The first patient saw a crowd of people and a television with indistinct faces in an office-shaped room on the right side, a man wearing light grey, and a women dressed in burgundy; the second patient saw red and green balls on the left side; the third patient saw coloured pieces of paper, newspapers, trees and people on the left side; the fourth patient saw coloured balls and nested circles in the left side; and the last patient saw his own small child moving and playing. The hallucinations occurred when the patients were completely awake and the patients reported that they knew that they were not real. The hallucinations continued all day, and were not associated with loss of consciousness, convulsions or abnormal behaviours.

Electroencephalography (EEG) performed while the patients were symptomatic or shortly thereafter showed mild bioelectrical slowing in the right hemisphere of a patient with a lesion in the right PCA territory, while the other patients' EEGs were normal (Table 1). The mean standardized Mini-Mental test score was $27 \pm 1.58$ (range 25-29). Neuro-ophthalmological examinations performed by an ophthalmologist were normal.

\begin{tabular}{|c|c|c|c|c|c|c|}
\hline $\begin{array}{l}\text { Patient } \\
\text { number }\end{array}$ & Age/Sex & $\begin{array}{l}\text { Diffusion- } \\
\text { weighted MRI }\end{array}$ & Visual Field Defect & EEG & $\begin{array}{l}\text { Characteristics } \\
\text { hallucinations }\end{array}$ & $\begin{array}{l}\text { Duration } \\
\text { hallucinations }\end{array}$ \\
\hline 1 & $62 / \mathrm{M}$ & $\begin{array}{l}\text { Left occipital lobe } \\
\text { infarct }\end{array}$ & $\begin{array}{l}\text { Right homonymous } \\
\text { hemianopsia }\end{array}$ & Normal & $\begin{array}{l}\text { Crowd of people and a } \\
\text { television with indistinct faces } \\
\text { in an office-shaped room on } \\
\text { the right side, a man wearing } \\
\text { light grey and a women } \\
\text { dressed in burgundy }\end{array}$ & Any time \\
\hline 2 & $84 / \mathrm{M}$ & $\begin{array}{l}\text { Right occipital lobe } \\
\text { infarct }\end{array}$ & $\begin{array}{l}\text { Left homonymous } \\
\text { hemianopsia }\end{array}$ & $\begin{array}{l}\text { Mild bioelectrical } \\
\text { slowing }\end{array}$ & $\begin{array}{l}\text { Red and green balls on the left } \\
\text { side }\end{array}$ & Any time \\
\hline 3 & $78 / F$ & $\begin{array}{l}\text { Right occipital lobe } \\
\text { infarct }\end{array}$ & $\begin{array}{l}\text { Left homonymous } \\
\text { hemianopsia }\end{array}$ & Normal & $\begin{array}{l}\text { Coloured pieces of paper, } \\
\text { newspapers, trees, and people } \\
\text { on the left side }\end{array}$ & Any time \\
\hline 4 & $81 / \mathrm{M}$ & $\begin{array}{l}\text { Bilateral occipital } \\
\text { lobe infarct }\end{array}$ & $\begin{array}{l}\text { Left homonymous } \\
\text { hemianopsia }\end{array}$ & Normal & $\begin{array}{l}\text { Coloured balls and nested } \\
\text { circles in the left side }\end{array}$ & Any time \\
\hline 5 & $54 / \mathrm{M}$ & $\begin{array}{l}\text { Bilateral occipital } \\
\text { lobe infarct }\end{array}$ & $\begin{array}{l}\text { Left homonymous } \\
\text { hemianopsia }\end{array}$ & Normal & $\begin{array}{l}\text { His own small child moving } \\
\text { and playing }\end{array}$ & Any time \\
\hline
\end{tabular}

Table 1: Distribution of findings and characteristics of hallucinations.

None of the patients had been treated. When assessed during follow-up, the visual hallucinations remained in all patients for up to 3 months without any specific treatment, and only homonymous hemianopsia remained as a sequelae.

\section{Discussion}

The etiology of CBS is unclear. However, two important mechanisms have been proposed. The first of these is the release phenomenon. The main factor involved is sensory deprivation. Where ocular pathologies reduce sensory input, the visual association areas are affected, which leads to a reduction in the suppression of the high cortical centres, and previously subconscious perceptions are 'released' into consciousness, resulting in a visual hallucination. This mechanism is equivalent to the phantom limb syndrome following limb amputation $[14,15]$. The second theory is the currently accepted theory of deafferentation, in which the absence of cortical visual sensory input due to visual impairment leads to visual hallucinations, with increased frequency of spontaneous discharge and disinhibition of neurons in the visual association cortex [5]. Ashwin observed vivid images of lions and cats, a flock of birds, a pack of hounds, chessboards and brightly coloured scarves in the hemianopic field following an occipital lobe infarct as the visual pathway was intact to the cortex and these visual hallucinations were generated from the infarcted occipital cortex ("inverse phantom vision") [16].

When studied during hallucinations, functional MRI shows increased activity in the ventral occipital lobe, while single photon emission computed tomography shows hyperperfusion in the lateral 
temporal cortex, striatum, and thalamus, suggesting that these areas contribute to the formation of hallucinations $[17,18]$.

Charles Bonnet syndrome is characterized by the presence of complex, structured visual hallucinations in the form of people, faces, animals or trees. These may be white or coloured, static or animated $[4,19]$. While some of our patients saw simple shapes, balls, or circles, their other hallucinations were more complex, such as their office or a child.

The clinical course may be episodic, cyclic or chronic. While the duration is usually less than 12 months, they may persist for several years [4]. Santos Bueso et al. reported complex hallucinations that mainly involved people and faces, with movement and colour; their patient had daily episodes lasting between 3 and 5 min that evolved over 6-12 months [20]. Our patients' hallucinations lasted from a few minutes to half an hour and all disappeared within 3 months.

Cox and ffytche reported that the majority of people with CBS felt that the hallucinations had no real effect on their lives $(60 \%)$, although a subset judged them to have fairly $(25 \%)$ or very $(8 \%)$ negative effects, and $6 \%$ reported a fairly or very pleasant effect (1\%). Although initially known as "pleasant or neutral" symptoms and not an emotional burden, it has subsequently been shown that CBS creates an emotional burden in patients. CBS patients rarely have unpleasant symptoms $[1,21]$. Nevertheless, Santhouse et al. reported that the hallucinations were an emotional burden in $50 \%$ of 34 patients, and half of them were egodystonic [22]. Similarly, Vukicevic and Fitzmaurice reported that the syndrome caused moderate or severe stress in 16 of 35 patients [23].

Therefore, CBS may require treatment. The treatment should be individualized and include everything related to the aetiopathology of the syndrome. Comprehensive treatment includes providing adequate information to patients and their families, increasing the patient's quality of life, and treating the cause or anxiety disorder secondary to the symptoms. Several anticonvulsant, antipsychotic, and antidepressant agents have been tried, including carbamazepine, valproate, gabapentin, levetiracetam, haloperidol, olanzapine, risperidone, mirtazapine, venlafaxine, citalopram, donepezil, melperone and ondansetron [24-29].

The visual hallucinations had no effects on the daily functions of our patients. The described hallucinations were not egodystonic in any of our patients, and the patient who saw a child actually enjoyed the hallucination. In our other patients, the hallucinations were neutral and did not require treatment.

The hallucinations seen in mental disorders are mostly auditory hallucinations. Visual hallucinations are less frequent than auditory hallucinations in psychotic disorders and are related to the psychotic core, which is generally present in terms of content. The hallucinations are often accompanied by delusions or other manifestations of the mental disorder, such as schizophrenia and related mental disorders, or are accompanied by depression or mania in mood disorders.

Alcoholic hallucinosis is a rare psychiatric disorder in which isolated hallucinations dominate the picture and is distinguished from CBS by a history of chronic alcohol abuse.

Visual hallucinations can occur in patients with occipital lobe epilepsy (OLE). A diagnosis of OLE was excluded in all of our patients because they did not have epileptic activity in their EEG and the hallucinations occurred during or immediately before the EEG examination. In addition, none of our patients were treated and the hallucinations disappeared within 3 months.

In elderly patients, hallucinations are frequently seen during the course of neurological disorders, such as Alzheimer's disease and Parkinson's disease or mental disorders such as delirium, psychosis, bipolar disorder, and drug abuse. The most common psychotic symptom in Parkinson's disease is that of visual hallucinations, with a prevalence of $22 \sim 38 \%$ [30]. None of our patients had a history of psychiatric illness or substance use. There were no signs of dementia or Parkinson's disease in any of our patients.

\section{Conclusion}

This paper is intended to increase the awareness of CBS, which we think is more common than believed. A diagnosis of CBS requires evaluation by a multidisciplinary team that includes neurologists, ophthalmologists, and psychiatrists, especially in elderly patients. It is important to ask about hallucinations in detail and perform an EEG and MRI to rule out OLE.

\section{References}

1. Teunisse RJ, Cruysberg JR, Hoefnagels WH, Verbeek AL, Zitman FG (1996) Visual hallucinations in psychologically normal people: Charles Bonnet's syndrome. Lancet 347: 794e797.

2. Bonnet C (1760) Analytical test on the aculties of the soul. Copenhagen: Ferres \& Philibert, pp: 426-429.

3. de Morsier G (1967) The Charles Bonnet syndrome: Visual hallucinations in the aged without mental de ciency. Ann Med Psychol (Paris) 2: 678-702.

4. Santos-Bueso E, Sáenz-Francés F, Serrador-García M, Porta-Etessam J, Martínez-de-la-Casa JM, et al. (2014) Prevalence and clinical characteristics of Charles Bonnet syndrome in Madrid, Spain. Eur J Ophthalmol 24: 960-963.

5. Burke W (2002) The neural basis of Charles Bonnet hallucinations: A hypothesis. J Neurol Neurosurg Psychiatry 73: 535-541.

6. Tan CS, Sabel BA, Goh KY (2006) Visual hallucinations during visual recovery after central retinal artery occlusion. Arch Neurol 63: 598-600.

7. Madill SA, Ffytche DH (2005) Charles Bonnet syndrome in patients with glaucoma and good acuity. Br J Ophthalmol 89: 785-786.

8. Toosy AT, Roberton BJ, Jayaram H, Plant GT (2006) Monocular complex visual hallucinations and their suppression by eye closure. Eye 20: 732-733.

9. Choi EJ, Lee JK, Kang JK, Lee SA (2005) Complex visual hallucinations after occipital cortical resection in a patient with epilepsy due to cortical dysplasia. Arch Neurol 62: 481-484.

10. Freiman TM, Surges R, Vougioukas VI, Hubbe U, Talazko J, et al. (2004) Complex visual hallucinations (Charles Bonnet syndrome) in visual field defects following cerebral surgery report of four cases. J Neurosurg 101: 846-853.

11. Rovner BW (2006) The Charles Bonnet syndrome: A review of recent research. Curr Opin Ophthalmol 17: 275-257.

12. Kumral E, Uluakay A, Dönmez İ (2015) Complex visual hallucinations following stroke: Epileptic origin or a deafferentation phenomenon? Neurologist 20: 13-15

13. Kölmel HW (1985) Complex visual hallucinations in the hemianopic eld. J Neurol Neurosurg Psychiatry 48: 29-38.

14. Cogan DG (1973) Visual hallucinations as release phenomena. Graefes Arch Klin Exp Ophthalmol 188: 139-150.

15. Hart J (1997) Phantom visions: Real enough to touch. Elder Care 9: $30-32$. 
Citation: Senadim S, Balcik ZE, Uygun E, Yusifov M, Tekin B, et al. (2017) Visual Hallucinations and Ischemic Stroke: Review of 5 Cases. J Neurol Neurophysiol 8: 440. doi:10.4172/2155-9562.1000440

Page 4 of 4

16. Ashwin PT, Tsaloumas MD (2007) Complex visual hallucinations (Charles Bonnet syndrome) in the hemianopic visual field following occipital infarction. J Neurol Sci 263: 184-186.

17. Ffytche DH, Howard RJ, Brammer MJ, David A, Woodruff P, et al. (1998) The anatomy of conscious vision: An fMRI study of visual hallucinations. Nat Neurosci 1: 738-742.

18. Adachi N, Watanabe T, Matsuda H, Onuma T (2000) Hyperperfusion in the lateral temporal cortex, the striatum and the thalamus during complex visual hallucinations: Single photon emission computed tomography findings in patients with Charles Bonnet syndrome. Psychiatry Clin Neurosci 54: 157-162.

19. Gonzalez-Delgado M, Tunon A, Salas-Puig J (2004) Síndrome de Charles Bonnet. Neurologia 19: 80-82.

20. Santos-Bueso E, Serrador-García M, Porta-Etessam J, Rodríguez-Gómez O, Martínez-de-la-Casa JM, et al. (2015) Charles Bonnet syndrome. A 45 case series. Rev Neurol 60: 337-340.

21. Cox TM, Hffytche D (2009) Negative outcome Charles Bonnet Syndrome. Br J Ophthalmol 98: 1236-1239.

22. Santhouse AM, Howard RJ, Ffytche DH (2000) Visual hallucinatory syndromes and the anatomy of the visual brain. Brain 123: 2055-2064.

23. Vukicevic M, Fitzmaurice K (2008) Butterflies and black lacy patterns: The prevalence and characteristics of Charles Bonnet hallucinations in an Australian population. Clin Experiment Ophthalmol 36: 659-665.
24. Batra A, Bartels M, Wormstall H (1997) Therapeutic options in Charles Bonnet syndrome. Acta Psychiatr Scand 96: 129-133.

25. Siddiqui Z, Ramaswmay S, Petty F (2004) Mirtazapine for Charles Bonnet syndrome. Can J Psychiatry 49: 787-788.

26. Moja CM, Milano E, Gasverde S, Gianelli M, Giordana MT (2005) Olanzapine therapy in hallucinatory visions related to Bonnet syndrome. Neurol Sci 26: 168-170.

27. Ukai S, Yamamoto M, Tanaka M, Takeda M (2004) Treatment of typical Charles Bonnet syndrome with donepezil. Int Clin Psychopharmacol 19: 355-357.

28. Lang UE, Stogowski D, Schulze D, Domula M, Schmidt E, et al. (2007) Charles Bonnet Syndrome: Successful treatment of visual hallucinations due to vision loss with selective serotonin reuptake inhibitors. J Psychopharmacol 21: 553-555.

29. Grüter T, Ayzenberg I, Gold R, Börnke C (2016) Charles Bonnet syndrome successfully treated with levetiracetam. J Neurol 263: 1872-1875.

30. Fénelon G, Alves G (2010) Epidemiology of psychosis in Parkinson's disease. J Neurol Sci 289: 12-17. 